\title{
A Correlational Study on Dispositional Resilience, Psychological Well-being, and Coping Strategies in University Students
}

\author{
Elisabetta Sagone*, Maria Elvira De Caroli \\ Department of Educational Sciences, University of Catania, Sicily, Italy \\ *Corresponding author: esagone@unict.it
}

Received May 26, 2014; Revised June 21, 2014; Accepted June 24, 2014

\begin{abstract}
This study concerned the relationships among the dispositional resilience, the dimensions of psychological well-being, and the coping strategies in a sample of 183 Italian university students aged 20-26 years and recruited from three Degree Courses at University of Catania (East Sicily, Italy). The following scales were used: 1) the Dispositional Resilience Scale-II to explore the factors of positive attitude, helplessness/alienation, and rigidity; 2) the Psychological Well-Being Scales clustered in six dimensions named autonomy, environmental mastery, purpose in life, positive relations with others, personal growth, and self-acceptance; 3) the COPE Inventory to analyze the five coping strategies defined as social support, reinterpretation, avoidance, problem solving, humor/turning to religion. Results indicated that high levels of positive attitude were correlated positively with the strategies of reinterpretation and problem solving, but negatively with avoidance coping, and high levels of helplessness/alienation were related positively to avoidance. Moreover, high levels of positive attitude were positively correlated with almost all dimensions of psychological well-being; high levels of helplessness/alienation were negatively correlated with psychological well-being. Finally, almost all dimensions of psychological wellbeing were correlated negatively with avoidance strategy and positively with problem solving coping; in addition, personal growth was positively correlated with reinterpretation. Implications for future educational trainings, centered on the effects of resilience and coping strategies on psychological well-being, will be discussed.
\end{abstract}

Keywords: resilience, psychological well-being, coping strategy, university students

Cite This Article: Elisabetta Sagone, and Maria Elvira De Caroli, “A Correlational Study on Dispositional Resilience, Psychological Well-being, and Coping Strategies in University Students.” American Journal of Educational Research, vol. 2, no. 7 (2014): 463-471. doi: 10.12691/education-2-7-5.

\section{Introduction}

Scientific literature underlined that the relationships existing between resilience as dispositional trait and psychological well-being, between coping strategies and well-being, as well as between dispositional resilience and coping strategies, are considered some of the most interesting topics in educational positive psychology [1], in different domains of human development and according to the life-span perspective [2].

The aim of this paper was to analyze these relationships in a sample of university students attending the degree courses (Medicine, Engineering, and Law Degree Courses) at University of Catania, Sicily (Italy). The choice of these three groups of university students was addressed by two main reasons. The first one was linked to widely diffused academic status of these students, in our context, characterized by higher levels of procrastination and longer periods of permanence in academic settings, compared to other students. Accordingly to several empirical evidences, researchers identified some psychological characteristics defining the "typical procrastinators". For example, it was observed that students with high levels of stress and low self-efficacy at self-regulation reported high levels of academic procrastination [3], as well as students who were likely to use self-handicapping strategies and inadequate coping with failures showed high levels of academic procrastination $([4,5])$.

The second reason was linked to higher vulnerability and lower levels of physical and psychological well-being in medical university students than the others $([6,7])$. As reported in Supe's research [8], higher levels of stress were found in medical students who used the coping strategies as positive reappraisal, accepting responsibility, and planful problem solving, whilst lower levels of stress were noted in medical students who adopted the escaping strategy and distancing from difficult situations. More recently, some researchers discovered that medical university students with low levels of resilience but high levels of optimism showed a great psychological wellbeing [9].

\subsection{Dispositional Resilience as Personality Trait of Hardy People}


Resilience has been considered as a dispositional trait or personal quality that allows people to overcome hardships and thrive in the face of them, typically present in hardy people (e.g., [10,11,12]). This construct was initially defined as a personality characteristic that moderates the negative effects of stress and promotes adaptation [13], the ability to restore or maintain internal or external equilibrium under significant threat by means of human activities including thought and action [14], as well as the ability to have positive outcomes in the face of adversity [15]. More recently, resilience has been considered as the ability to bounce back or recover from stressful circumstances in order to reach a whole adjustment to environment (e.g., [16,17,18]). Some researchers argued that highly resilient individuals were generally better at maintaining their physical and psychological health and at having the ability to recover themselves more quickly from stressful events than lowly resilient ones [19]. Other researchers found that undergraduate students greatly able to bounce back from adversities were more ego-resilient and optimistic individuals, engaged in positive social relationships and get used to apply the coping strategies of acceptance, active coping, and positive reframing than those unable to do it [16]. Some researchers observed sex differences on factors of resilience, in the sense that women scored higher than men in helplessness/alienation while men reported higher scores than women in positive attitude [20]; additionally, boys tended to be more resilient in personal competence than girls [21].

Among the most applied quantitative measures of resilience, it is possible to mention:

- the Wagnild and Young's Resilience Scale [13] with two main factors called personal competence and acceptance of self and life;

- the Bartone et al.'s Dispositional Resilience Scale [12], including the positive factors of hardiness, named as control (that is, a feeling of control over life circumstances), commitment (that is, a feeling of deep involvement and tendency to engage fully in life activities), and challenge (namely, experimentation of life changes or obstacles as exciting possibilities for selfdevelopment);

- the Friborg et al.'s Resilience Scale for Adults [22], as well as the Hjemdal et al.'s Resilience Scale for Adolescents [23] with a five-factors solution including personal strength, social competence, family cohesion, structured style, and social resources;

- the Connor-Davidson's Resilience Scale [24], grouping the factors of personal competence and tenacity, acceptance of change, tolerance of stress and negative feelings, personal control, and spirituality.

The framework of the current study referred to factors of resilience was constituted by Sinclair and Oliver's model of hardiness [11], according to which the three factors, called helplessness, alienation, and rigidity, represented respectively the negative polarities of the three positive factors of dispositional resilience (control, commitment, and challenge). Specifically, control is defined as the tendency to think, feel and act as if one is influential, rather than helpless, in the face of the various contingencies of life; individuals with high control do not ingenuously expect to determine all outcomes but rather perceive themselves as being able to make the difference through their choices. Commitment is named as the tendency to involve oneself in, rather than experience alienation from, whatever one is doing or encounters in everyday life; highly committed individuals express a global sense of purpose that allows them to find the meaning of the people, events and things of their environment. Finally, challenge is considered as the tendency to believe that change, in opposition to stability, is a normal condition and that changes are interesting incentives to growth rather than threats to one's security; so, individuals with high challenge are open to all new experiences, flexible in the face of changes, and tend to put up with the ambiguity in an exploratory way.

\subsection{Psychological Well-being as Factor of Optimal Functioning}

Psychological well-being has been considered as a set of psychological characteristics involved in positive human functioning $([25,26])$ that included several resilience-related and hardiness-related dimensions. According to the Ryff's "eudaimonic perspective” ([27], [28]), the most important elements of psychological wellbeing were represented by self-acceptance (in terms of self-actualization, optimal functioning, and maturity); positive relations with other individuals (linked to the ability to express feelings of empathy and affection for all human beings and to be able of greater love and friendship, and identification with the others); autonomy (considered as self-determination, independence, and regulation of behavior through internal locus of control); environmental mastery (in terms of the ability to create environments suitable to his or her healthy conditions); purpose in life (including a sense of goal directedness and intentionality); and, finally, personal growth (defined as the realization of one's potentialities, continuing to develop oneself as a person and underlining the importance of new challenges at different moments of life).

The paradigm of psychological well-being has been analyzed in relation to other constructs such as resilience and hardiness ([29,30,31]), adaptive coping strategies [32], sense of coherence [33], humor styles [34], self-esteem [35]. For example, some researchers found that the dimensions of psychological well-being (except for the autonomy) were positively correlated with dispositional resilience analyzed using the factors of commitment, control, and challenge [31]. Also, significant correlations among psychological well-being, internal locus of control, positive functioning, and high levels of self-esteem in younger, middle-aged, and older adults were observed [36]. More recently, in Italian school context, it was noted that the more the individuals were able to choose contexts suitable to personal needs (environmental mastery), to see themselves as growing and expanding (personal growth), and to perceive themselves as self-satisfied (selfacceptance), the more they were resilient [37]. In addition, positive relationships between generalized self-efficacy and environmental mastery, personal growth, and selfacceptance were found [38]: so, highly efficient individuals expressed higher scores in these dimensions than lowly efficient ones.

Relevant differences for sex and age variables were found in relation to psychological well-being ([36,39]): in fact, boys scored higher in environmental mastery, 
purpose in life, and self-acceptance than girls, as well as late adolescents scored higher on personal growth and positive relations with others than adults and the elderly.

One of the most famous and complete measures of the abovementioned paradigm was represented by the Psychological Well-Being Scales, created by Ryff and Singer $([27,40])$ and adapted to different contexts by other researchers (e.g., [36,39,41,42]). These scales measured the six dimensions of well-being for each of which it is possible to reach high vs. low levels of self-acceptance, high vs. low levels of autonomy, and so on. In some studies $([33,42])$, scholars found a good concurrent validity of PWBS and significant correlations between the PWBS and other measures of subjective well-being as "life satisfaction" [43], "sense of vitality" [44], and “optimistic orientation” ([45,46]).

\subsection{Adaptive vs. Maladaptive Coping Strategies}

From the findings of Lazarus and Folkman [47], coping strategies were recognized as positive and/or negative dispositions to cope with difficulties and unexpected events. Subsequently, Carver and his colleagues [48] defined the following adaptive versus maladaptive strategies, extending the marked distinction between problem-focused and emotion-focused coping:

- the active coping was defined as an activity directed toward the removal of stressors;

the planning was considered as a thinking about the best way to handle the problem;

- the suppression of competing activities as elimination of competing channels of information in order to concentrate fully on the stressors only;

- the restraint coping was defined in terms of a waiting strategy to deal appropriately with the difficulty;

- the seeking of instrumental and emotional social support as an activity of support seeking from other sources or people;

- the focus on and venting of emotions was considered as a dysfunctional activity fixed on negative emotions for a long time exacerbating the distress;

- the mental and behavioral disengagement as reduction of one's efforts to solve the problem, distracting oneself with alternative activities (e.g., watching TV, drinking alcohol, to go shopping or other diversions);

- the positive reinterpretation and growth in terms of direct managing of stressful conditions, modifying actively the meaning of the same situation;

- the acceptance was defined as an engagement strategy functional to both recognize the presence of the problem and try to deal with the same problem;

- the denial as refusal of the existence of stressful events or avoidance of reality of problems;

- finally, the turning to religion as coping strategy for emotional comfort with the help of external sources.

These strategies were grouped in primary and secondary appraisal and considered both as individual dispositions in one's everyday life and as situationspecific coping tendencies.

Several investigations found that individuals with high levels of resilience, life satisfaction, and optimism tended to adopt the positive and adaptive coping strategies as task-oriented, active, and planful coping, whilst those with high levels of pessimism were likely to use the maladaptive strategies as disengagement, denial, and venting of emotions (e.g., [49,50]). Some scholars found that medical university students with high levels of life satisfaction were less likely to use emotion-focused strategies, such as wishful thinking, than the others [51].

Sex differences in the use of coping strategies were found: in fact, girls were likely to use the seeking social support and venting of emotions, while boys were likely to adopt the mental and behavioral disengagement [48]. Girls tended to use the engagement in social relationships and the creation of change as coping strategies more frequently than boys, whereas boys were more likely to adopt diversion coping strategy than girls [52]. Additionally, women scored significantly higher than men on the emotional and avoidance coping styles and lower on the rational and detachment coping [53].

Among the most cited measures applied to analyze the coping strategies, it is noteworthy the "Ways Coping Questionnaire" [54], used with older adults and composed by eight subscales to assess the following strategies: confrontive coping, distancing, self-controlling, seeking social support, accepting responsibility, escape-avoidance, planful problem solving, and positive reappraisal. Additionally, the authors created a revised version for undergraduate students, focused on the evaluation of problem-focused coping, wishful thinking, detachment, seeking social support, focusing on the positive, selfblame, tension reduction, and keep to self strategy.

The "Coping Inventory for Stressful Situation" and the related version "CISS: Situation-Specific Coping Scale”, created by Endler and Parker [55], were other frequently diffused measures used to assess three main strategies to cope with stress in multiple circumstances (task-oriented, emotion-oriented, and avoidance-oriented coping articulated in two sub-scales: distraction and social diversion) and applied to adolescents, university students, and adults. Finally, the "Coping Orientation for Problem Experiences”, called COPE Inventory ([48,56]), was a self-report questionnaire used to measure individual differences in adaptive and maladaptive coping strategies in undergraduate students.

The framework of the current study in relation to coping strategies was referred to the articulation provided by Sica and her colleagues in Italian context [57], according to which the main strategies to cope with stressful situations in daily life were linked to the positive reinterpretation of the events meaning and active research of solutions (in terms of problem-focused coping), the seeking for social support, turning to religion, and the use of humor coping (in terms of emotion-focused coping), and, finally, the avoidance coping.

\subsection{Purpose of Study}

The purpose of the current study was to examine the relationships among the dispositional resilience, the dimensions of psychological well-being, and the coping strategies in three groups of Italian university students at University of Catania, Sicily (Italy).

\subsubsection{Hypotheses}

We hypothesized that high levels of resilience will be related positively to problem-focused coping strategies 
(that is, problem solving and positive reinterpretation) $\left(\mathrm{H}_{1 \mathrm{a}}\right)$ but negatively to emotion-focused (that is, social support and humor/turning to religion) and avoidance ones $\left(\mathrm{H}_{1 \mathrm{~b}}\right)$; high levels of resilience will be positively related to psychological well-being $\left(\mathrm{H}_{2}\right)$; high levels of psychological well-being will be related positively to problem-focused coping strategies $\left(\mathrm{H}_{3 a}\right)$ but negatively to emotion-focused and avoidance ones $\left(\mathrm{H}_{3 \mathrm{~b}}\right)$.

As a corollary, in relation to differences for type of degree course, we expected that medical university students will score lower on levels of resilience $\left(\mathrm{H}_{4 \mathrm{a}}\right)$ and psychological well-being $\left(\mathrm{H}_{4 \mathrm{~b}}\right)$ and will use emotionfocused and avoidance coping strategies $\left(\mathrm{H}_{4 \mathrm{c}}\right)$ more than law and engineering ones. For differences about the levels of procrastination, we expected that highly procrastinated university students will score lower on resilience $\left(\mathrm{H}_{5 \mathrm{a}}\right)$ and psychological well-being $\left(\mathrm{H}_{5 \mathrm{~b}}\right)$, and use the problemfocused coping strategies (that is, problem solving and positive reinterpretation) more than emotion-focused (that is, social support and humor/turning to religion) and avoidance ones, compared to the other colleagues $\left(\mathrm{H}_{5 \mathrm{c}}\right)$.

Finally, accordingly to sex differences emerged from previous and above-mentioned studies, we expected that boys will be more resilient than girls $\left(\mathrm{H}_{6 \mathrm{a}}\right)$; boys will score higher than girls on environmental mastery, purpose in life, self-acceptance, autonomy, and personal growth, while girls will score higher than boys on positive relations with others $\left(\mathrm{H}_{6 \mathrm{~b}}\right)$; finally, girls will be more likely to use emotion-focused coping strategies than boys while boys will be more likely to adopt problem-focused and avoidance strategies than girls $\left(\mathrm{H}_{6 \mathrm{c}}\right)$.

\subsubsection{Participants}

The sample consisted of 183 Italian university students (94 boys and 89 girls) recruited from the degree courses of Medicine $(n=60)$, Engineering $(n=61)$, and Law $(n=62)$ at University of Catania, Sicily (Italy). Demographic information were collected at the beginning of the fall semester of academic year 2013-2014. Participants were chosen with random sampling method among those characterized by low (48,1\%), intermediate $(20,2 \%)$ and high "procrastination" (31,7\%). The age of university students ranged from 20 to 26 years $(M=22.8$, sd=1.4).

\subsubsection{Measures and Procedure}

We used a self-report and anonymous questionnaire, administered in a small group setting by an expert researcher, consisting of the three following scales: the Italian version of Dispositional Resilience Scale-II (DSRII: $[11,20])$, the Italian short version of Psychological Well-Being Scales (PWB: [58,59]), and the Italian version of COPE Inventory ([48,57]).

The Dispositional Resilience Scale-II was a 18-item version scale, elaborated by Sinclair and Oliver [11] and recently translated and adapted to Italian context by Prati [20]. This scale was useful to explore the six factors typically integrated in the constructs of resistance and vulnerability to stressful events in everyday life: 1) commitment, 2) control, 3) challenge, 4) powerlessness, 5) alienation, and 6) rigidity. Each item was rated according to a 5-point Likert-type scale, from 1 (corresponding to "strongly disagree") to 5 intervals (corresponding to "strongly agree"). We used the 17-item version with threefactors solution: positive attitude (eight items), rigidity (three items), and helplessness/alienation (six items). Some examples of items included in each factor of resilience were: e.g., "My successes are because of my efforts and abilities" (positive attitude), "I carefully plan just about everything I do" (rigidity), and "I often feel alienated from the people around me" (helplessness and alienation). Participants were presented with the following instructions: "Each of these statements reflects ways people sometimes feel. Please I invite you to indicate the extent to which you agree with each of the undermentioned statements". The internal consistency of DRS, using the Cronbach's alpha coefficient, was considered acceptable and ranged from .61 to .65.

The Psychological Well-Being Scales, created by Ryff and Singer [60], were composed by 64 items, each valuable on a 6-point Likert-type scale from 1 (anchored with "strongly disagree") to 6 intervals (anchored with "strongly agree"). These items were clustered in the six following subscales: autonomy, environmental mastery, purpose in life, positive relations with others, personal growth, and self-acceptance. Some examples of items included in each factor of psychological well-being were: e.g., "I have confidence in my opinions, even if they are contrary to the general consensus" (autonomy), "I am quite good at managing the many responsibilities of my daily life” (environmental mastery), "I am an active person in carrying out the plans I set for myself" (purpose in life), "I know that I can trust my friends, and they know they can trust me" (positive relations with others), "I have the sense that I have developed a lot as a person over time” (personal growth), and "I like most aspects of my personality" (selfacceptance). In this study, we used the short version with 18 items, translated and applied to Italian context by Zani and Cicognani [59]. Participants were asked to indicate the extent to they agreed with the mentioned statements. The internal consistency of PWB was satisfactory $(\alpha=.71)$ and ranged from .68 to .75 for each subscale.

Finally, the COPE Inventory [48], recently adapted to Italian university students by Sica and her colleagues [57], was formed by 60 items, each valuable on a 4-point rating scale from 1 (anchored with "I usually don't do this at all”) to 4 intervals (anchored with "I usually do this a lot"). This inventory was functional to analyze the following five coping strategies: 1) social support, 2) positive reinterpretation, 3) avoidance, 4) problem solving, and 5) humor and turning to religion. Some examples of items included in each coping strategy were: e.g., "I talk to someone to find out more about the situations" (social support), "I make sure not to make matters worse by acting too soon" (positive reinterpretation), "I refuse to believe that it has happened" (avoidance), "I concentrate my efforts on doing something about it” (problem solving), and "I laugh about the situation", "I put my trust in God" (humor and turning to religion). Participants were presented with the following instructions: "We are interested in how people respond when they confront difficult or stressful events in their lives. There are lots of ways to try to deal with stress. This questionnaire asks you to indicate what you generally do and feel, when you experience stressful events. Obviously, different events bring out somewhat different responses, but think about what you usually do when you are under a lot of stress. Indicate what you usually do when you experience a stressful event”. 
The internal consistency of COPE was satisfactory for total scale $(\alpha=.81)$ and Cronbach's alpha coefficient of each subscale ranged from .68 to .88 .

\subsubsection{Data Analysis}

Data analysis was performed by means of the Statistical Package for the Social Sciences (SPSS 20 for Windows 7) using t-tests, ANOVA, and Pearson's linear correlations. Additionally, we applied linear regressions with stepwise method using factors of resilience and coping strategies as predictor variables and psychological well-being as predicted variable. A $p$-value of .05 was used to determine statistical significance in all analyses.

Sex (boy vs. girls), procrastination (low vs. intermediate vs. high procrastination), and type of degree course (Medicine, Engineering, and Law Degree Courses) were used as independent variables, while scores of DRS, PWB, and COPE were used as dependent variables.

\section{Results and Discussion}

\subsection{Dispositional Resilience}

Descriptive analyses for the factors of dispositional resilience showed that university students scored higher on positive attitude $(\mathrm{M}=3.66, \mathrm{sd}=.53)$ than rigidity $(\mathrm{M}=2.52, \mathrm{sd}=.88)$ and helplessness/alienation $(\mathrm{M}=1.80$, sd=.62 $)(F(2,364)=334.71, p<.001)$, with moderate sex differences only for the factor of positive attitude $\left(t_{(181)}=1.97, p=.05\right)$ : so, boys obtained higher scores $(\mathrm{M}=3.74$, $\mathrm{sd}=.54)$ than girls $(\mathrm{M}=3.58, \mathrm{sd}=.50)$, indicating that they tended to express higher levels of control and personal commitment in reaching of established goals compared to their colleagues. No significant differences for procrastination and type of degree course were found.

\subsection{Psychological Well-being}

Descriptive analyses carried out for the six dimensions of psychological well-being demonstrated that university students reported higher levels of personal growth $(\mathrm{M}=14.81$, sd=2.34), autonomy $(\mathrm{M}=14.20$, sd=2.41), and positive relations with others $(M=14.01, \mathrm{sd}=2.55)$, than levels of environmental mastery $(\mathrm{M}=12.56$, $\mathrm{sd}=2.11)$, purpose in life $(\mathrm{M}=12.48, \mathrm{sd}=2.41)$, and self-acceptance $(\mathrm{M}=12.62, \mathrm{sd}=2.48)(F(5,910)=44.05, p<.001)$.

Results showed significant sex differences for personal growth (M-boys=14.49, sd=2.40; M-girls=15.16, sd=2.23; $t_{(181)}=-1.94, p=.05$ ), positive relations with others (Mboys=13.63, $\mathrm{sd}=2.85$; M-girls=14.42, $\mathrm{sd}=2.13$; $t_{(181)}=-2.11$, $p=.03$ ), and purpose in life (M-boys=12.06, sd=2.53; Mgirls=12.92, $\left.\mathrm{sd}=2.20 ; t_{(181)}=-2.43, p=.01\right)$ : so, girls scored higher than boys on these three dimensions, indicating a greater feeling of continued development and sense of realizing of their potential, a strong sense of empathy and intimacy, and a good sense of directedness. No relevant differences for procrastination and type of degree course were noted.

\subsection{Coping Strategies}

Results of descriptive analyses for coping strategies indicated that university students were greatly likely to use the positive reinterpretation $(M=38.49$, $s d=5.63)$, problem solving $(\mathrm{M}=34.30$, sd=5.60), and social support coping $(\mathrm{M}=31.65$, sd=6.97), whilst tended to use the avoidance $(\mathrm{M}=26.19$, sd=6.57) and humor/turning to religion coping $(M=16.55, \mathrm{sd}=4.85)$ in a reduced way $(F(4,728)=438.10$, $p<.001)$.

Significant sex differences for coping strategies were found: it meant that girls reported higher scores for social

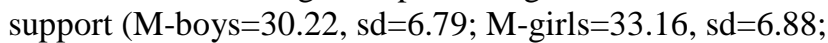
$\left.\mathrm{t}_{(181)}=-2.90, p=.004\right)$, but lower scores for humor/turning to religion coping (M-boys=17.37, sd=4.75; M-girls=15.70, $\left.\mathrm{sd}=4.83 ; t_{(181)}=2.27, p=.02\right)$ and avoidance strategy (Mboys=27.46, $\mathrm{sd}=7.32$; M-girls=24.85, $\mathrm{sd}=5.40 ; t_{(181)}=2.73$, $p=.007)$ compared to boys. These evidences underlined that girls were more likely than their colleagues to use the coping strategy focused on seeking of support from other people and resources; on the contrary, boys were more likely than girls to adopt strategies centered on the avoidance and the minimization of stressful situations, refusing the existence of stressors and the use of humoristic and religious coping style.

Differences for procrastination and type of degree course were not found in relation to the coping strategies.

\subsection{Relations among Constructs}

Pearson's linear correlations were carried out between the factors of dispositional resilience and coping strategies (DRS-COPE), the factors of dispositional resilience and dimensions of psychological well-being (DRS-PWB), and the dimensions of psychological well-being and coping strategies (PWB-COPE).

DRS-COPE. As observed in Table 1, statistical analyses showed that the positive attitude was correlated positively with reinterpretation and problem solving coping but negatively with avoidance; also, the rigidity was poorly and positively correlated with avoidance; finally, the helplessness/alienation was positively correlated with avoidance. These data meant that university students with high levels of dispositional resilience, specifically in relation to the ability to deal with challenges and manage their own environment, were likely to solve stressful situations by modifying the meaning of them in positive terms, and to search new and multiple problem solutions. Additionally, university students with high levels of alienation were likely to minimize stressful events refusing the existence of the same stressors.

No relevant and significant differences for sex, procrastination, and type of degree course were found about the correlations between the three factors of resilience and coping strategies.

Table 1. Dispositional resilience and coping strategy: linear correlations for total sample $(N=183)$

\begin{tabular}{|c|c|c|c|c|c|}
\hline \multirow{2}{*}{ DRS } & \multicolumn{5}{|c|}{ COPE } \\
\hline & I & II & III & IV & V \\
\hline I & .07 & $-.31 * *$ & $.32 * *$ & $.42 * *$ & .11 \\
\hline II & .14 & $.17^{*}$ & .03 & .06 & -.01 \\
\hline III & .05 & $.35^{* *}$ & -.07 & -.10 & -.01 \\
\hline \multicolumn{6}{|c|}{$\begin{array}{l}\text { Levels of significance for }(*) p<.05 \text { and }(* *) p<.01 \text {. } \\
\text { DRS-I: positive attitude; DRS-II: rigidity; DRS-III: alienation } \\
\text { COPE-I: social support; COPE-II: avoidance; COPE-III: positive } \\
\text { reinterpretation; COPE-IV: problem solving; COPE-V: humor and } \\
\text { turning to religion }\end{array}$} \\
\hline
\end{tabular}


DRS-PWB. As reported in Table 2, high levels of positive attitude were positively correlated with all dimensions of psychological well-being, except for purpose in life; so, it indicated that university students with high control and personal commitment in reaching of established goals and overcoming of stressful situations expressed a psychological condition characterized by generalized well-being.

Additionally, high levels of helplessness/alienation were negatively correlated with all dimensions of psychological well-being, except for purpose in life: these data revealed that university students with strong feelings of alienation and low sense of personal power were characterized by reduced generalized psychological wellbeing.

Also in this case, relevant and significant differences for sex, procrastination, and type of degree course were not observed about the correlations between factors of resilience and psychological well-being.

Table 2. Dispositional resilience and psychological well-being: linear correlations for total sample $(N=183)$

\begin{tabular}{|c|c|c|c|c|c|c|}
\hline \multirow{2}{*}{ DRS } & \multicolumn{6}{|c|}{ PWB } \\
\hline & I & II & III & IV & $\mathrm{V}$ & VI \\
\hline I & $.28^{* *}$ & $.45^{* *}$ & $.46^{* *}$ & $.27^{* *}$ & -.03 & $.42^{* *}$ \\
\hline II & -.09 & -.03 & -.14 & -.15 & .04 & $-.18^{*}$ \\
\hline III & $-.28 * *$ & $-.33 * *$ & $-.35 * *$ & $-.36^{* *}$ & -.05 & $-.44 * *$ \\
\hline \multicolumn{7}{|c|}{$\begin{array}{l}\text { Levels of significance for }\left(^{*}\right) p<.05 \text { and }(* *) p<.01 . \\
\text { DRS-I: positive attitude; DRS-II: rigidity; DRS-III: alienation } \\
\text { PWB-I: autonomy; PWB-II: environmental mastery; PWB-III: } \\
\text { personal growth; PWB-IV: positive relations with others; PWB-V: } \\
\text { purnose in life: PWB-VI: self-accentance. }\end{array}$} \\
\hline
\end{tabular}

PWB-COPE. As shown in Table 3, statistical analyses showed that autonomy, environmental mastery, personal growth, positive relations with others, and self-acceptance were negatively correlated with the avoidance strategy; on the contrary, autonomy, environmental mastery, personal growth, and self-acceptance were positively correlated with problem solving coping; finally, personal growth was positively correlated with positive reinterpretation.

Table 3. Psychological well-being and coping strategy: linear correlations for total sample $(N=183)$

\begin{tabular}{|c|c|c|c|c|c|}
\hline \multirow{2}{*}{ PWB } & \multicolumn{5}{|c|}{ COPE } \\
\hline & I & II & III & IV & $\mathrm{V}$ \\
\hline I & -.12 & $-.42 * *$ & $.16 *$ & $.28 * *$ & -.09 \\
\hline II & .04 & $-.36 * *$ & $.19 *$ & $.27^{* *}$ & -.01 \\
\hline III & .10 & $-.41 * *$ & $.32 * *$ & $.35 * *$ & -.02 \\
\hline IV & $.21^{* *}$ & $-.31 * *$ & .13 & .07 & -.06 \\
\hline $\mathrm{V}$ & .07 & $-.20 * *$ & .02 & .06 & .05 \\
\hline VI & .10 & $-.27 * *$ & $.25 * *$ & $.27 * *$ & .07 \\
\hline \multicolumn{6}{|c|}{$\begin{array}{l}\text { Levels of significance for }(*) p<.05 \text { and }(* *) p<.01 . \\
\text { PWB-I: autonomy; PWB-II: environmental mastery; PWB-III: } \\
\text { personal growth; PWB-IV: positive relations with others; PWB-V: } \\
\text { purpose in life; PWB-VI: self-acceptance. } \\
\text { COPE-I: social support; COPE-II: avoidance; COPE-III: positive } \\
\text { reinterpretation; COPE-IV: problem solving; COPE-V: humor and } \\
\text { turning to religion }\end{array}$} \\
\hline
\end{tabular}

These findings demonstrated that university students with a great personal autonomy, ability to create a context suitable to personal needs, sense of openness to experiences, feeling of trust with others, and positive representation of self-image tended to cope with stressful situations in proactive way, finding new solutions through the analysis of different possibilities. Moreover, university students who saw themselves as growing and expanding and open to new experiences tended to cope with unexpected and negative events by modifying the meaning of difficulties.

Sex differences were observed about the significant correlations between dimensions of psychological wellbeing and coping strategies:

-only for boy, autonomy was negatively related to social support $(r=-.30, p=.004)$; positive relations with others were negatively related to avoidance ( $r=-.38$, $p<.001$ ); finally, self-acceptance was positively related to problem solving $(r=.34, p=.001)$;

-only for girls, environmental mastery and personal growth were positively correlated with reinterpretation (respectively, $r=.32, p=.002 ; r=.42, p<.001$ ) and problem solving coping (respectively, $r=.30, p=.004 ; r=.50$, $p<.001$ ); relations with others were positively related to social support strategy $(r=.30, p=.004)$; finally, selfacceptance was related positively to reinterpretation $(r=.30, p=.005)$ and negatively to avoidance $(r=-.36$, $p=.001)$.

The deepening of these relationships, carried out by means of linear regressions with stepwise method, showed that psychological well-being was predicted positively by positive attitude of resilience $(\beta=.24, t=3.90, p<.001)$ and reinterpretation coping strategy $(\beta=.18, t=3.24, p<.001)$ but negatively by helplessness/alienation $(\beta=-.28, t=-4.76$, $p<.001)$ and avoidance coping strategy $(\beta=-.36, t=-6.21$, $p<.001)\left(R=.707 ; R^{2}=.489 ; F(4,182)=44.50, p<.001\right)$.

\section{Conclusions}

Findings of the present study highlighted the correlations among the dispositional resilience, the dimensions of psychological well-being, and the coping strategies in university students at University of Catania, Sicily (Italy). According to $\mathrm{H}_{1 \mathrm{a}}$, we hypothesized that high levels of resilience would be related positively to problemfocused coping strategies but negatively to emotionfocused and avoidance ones $\left(\mathrm{H}_{1 \mathrm{~b}}\right)$ : results confirmed that university students with positive attitude linked to challenge, commitment, and control (that is, factors typically owned by highly resilient individuals) were likely to adopt problem-focused strategies and avoid the escape from the stressful events. These data were consistent with findings of Smith et al. [16], Li and Yang [61], and Beasley and her colleagues [62].

In relation to $\mathrm{H}_{2}$, we predicted that high levels of resilience would be positively related to psychological well-being; also in this case, results confirmed that university students with positive attitude expressed high psychological well-being in almost all dimensions. These results could be considered similar to those obtained by Picardi et al. [31], Hurtes and Allen [63] and in line with the findings of Beasley et al.'s research [62], according to which the more the university students were resilient and hardy the more they felt themselves psychologically healthy.

Finally, according to $\mathrm{H}_{3 \mathrm{a}}$ and $\mathrm{H}_{3 \mathrm{~b}}$, we expected that high levels of psychological well-being would be related positively to problem-focused coping strategies but negatively to emotion-focused and avoidance ones. Results showed that university students who expressed a 
condition of psychological well-being handled actively problems and stressful events, without resorting to avoidance and escape strategies. These evidences were in line with the findings of Park and Adler [64] and Stewart et al. [7] in a sample of medical university students.

The absence of significant correlations between dimensions of psychological well-being and the specific humor/turning to religion coping in these groups of university students was in contrast with the evidences found in Kazarian and Martin's study [65] only for humor coping style: so, affiliative and self-enhancing humor styles were positively related to high psychological wellbeing. Additionally, only for religious coping, this lack of correlations was in contrast with Maltby et al.'s findings [66] according to which high levels of religiosity as coping mechanism positively predicted high levels of well-being.

One of the most interesting results emerged by the present study was given by significant relationships of alienation and avoidance with low levels of psychological well-being; it meant that the more the university students felt themselves as helpless and alone individuals, perceived their life without significance and denied the reality of problems, the more they tended to be dissatisfied with themselves and their own past life, isolated and frustrated in interpersonal relationships, to be greatly influenced by social pressures, unable to change or improve surrounding environment, and felt a sense of personal stagnation.

In relation to differences for type of degree course, we expected that medical university students would score lower on levels of resilience $\left(\mathrm{H}_{4 \mathrm{a}}\right)$ and psychological wellbeing $\left(\mathrm{H}_{4 \mathrm{~b}}\right)$ and would use emotion-focused and avoidance coping strategies $\left(\mathrm{H}_{4 \mathrm{c}}\right)$ more than law and engineering ones. Unexpectedly, medical university students obtained similar scores to those expressed by law and engineering ones.

Concerning the differences for levels of procrastination, we predicted that highly procrastinated university students will score lower on resilience $\left(\mathrm{H}_{5 \mathrm{a}}\right)$ and psychological well-being $\left(\mathrm{H}_{5 \mathrm{~b}}\right)$, and use the problem-focused coping strategies (that is, problem solving and positive reinterpretation) more than emotion-focused (that is, social support and humor/turning to religion) and avoidance ones, compared to the other colleagues $\left(\mathrm{H}_{5 \mathrm{c}}\right)$. Contrary to previous empirical evidences in scientific literature (e.g., [4,67,68]) and our initial expectations, differences linked to levels of procrastination in all three groups of university students were not observed.

The analysis of sex differences in relation to the aforementioned topics confirmed that boys were more resilient than girls $\left(\mathrm{H}_{6 \mathrm{6}}\right)$, although without a marked significance as noted by Prati [20]; girls scored higher than boys on positive relations with others $\left(\mathrm{H}_{6 \mathrm{~b}}\right)$ in line with Ryff and Singer's results [60] and, unexpectedly, on personal growth and purpose in life; finally, girls were more likely than boys to use the emotion-focused coping strategy based on social support in line with the evidences of Carver et al. [48] and Sica et al. [57], while boys tended to use the avoidance strategy more than girls as expected $\left(\mathrm{H}_{6 \mathrm{c}}\right)$.

The deepening of relationships among the three topics, carried out by analyzing the effects of resilience and coping strategies on well-being, demonstrated that positive attitude as resilient disposition and reinterpretation as adaptive coping strategy predicted positively conditions of psychological well-being in academic setting, while helplessness/alienation and avoidance as maladaptive coping strategy had negative effects on well-being. In this direction, it would be necessary to arrange supporting activities for university students (e.g., resiliency and hardiness trainings [69,70]; programs centered on academic self-efficacy and selfenhancing [71,72]) functional to empower resilience and tendency to use adaptive coping strategies.

Future investigations in academic context will compare groups of regular university students with groups of highly procrastinated ones on dimensions of well-being, resilience, and the use of coping strategies in relation to different educational trainings. In addition, the authors of this investigation underlined the importance of an integrated qualitative and quantitative approach that could be extensively functional to understand the intrinsic and extrinsic academic motivations to university students’ procrastination.

\section{References}

[1] Seligman, M.E.P., \& Csikszentmihalyi, M. (2000), Positive psychology: An introduction, American Psychologist, 55 (1), 5-14.

[2] Ryff, C.D., Singer, B., Love, G.D., \& Essex, M.J. (1998). Resilience in adulthood and later life: Defining features and dynamic processes. In J. Lomranz (Ed.), Handbook of Aging and Mental Health: An Integrative Approach (pp. 69-96). New York: Plenum Press.

[3] Klassen, R.M., Krawchuk, L.L., \& Rajani, S. (2008), Academic procrastination of undergraduates: low self-efficacy to selfregulate predicts higher levels of procrastination, Contemporary Educational Psychology, 33 (4), 915-931.

[4] Ferrari, J.R., Johnson, J.L., \& McCown, W.G. (1995), Procrastination and task avoidance: Theory, research, and treatment. New York: Plenum Press.

[5] Midgley, C., \& Urdan, T. (2001), Academic self-handicapping and performance goals: A further examination, Contemporary Educational Psychology, 26, 61-75.

[6] Mosley, T.H., Perrin, S.G., Neral, S.M., Dubbert, P.M., Grothues, C.A., \& Pinto, B.M. (1994), Stress, coping, and well-being among third-year medical students, Academic Medicine, 69 (9), 765-767.

[7] Stewart, S.M., Betson, C., Lam, T.H., Marshall, I.B., Lee, P.W.H., \& Wong, C.M. (1997), Predicting stress in first year medical students: a longitudinal study, Medical Education, 31 (3), 163-168.

[8] Supe, A.N. (1998), A study of stress in medical students at Seth G.S. Medical College, Journal of Postgraduate Medicine, 44 (1), 1-6.

[9] Souri, H., \& Hasanirad, T. (2011), Relationship between Resilience, Optimism and Psychological Well-being in Students of Medicine, Procedia - Social and Behavioral Sciences, 30, 15411544.

[10] Richardson, G.E. (2002), The metatheory of resilience and resiliency, Journal of Clinical Psychology, 58 (3), 307-321.

[11] Sinclair, R.R., \& Oliver, C.M. (2003), Development and validation of a short measure of hardiness. Defense Technical Information Center Report, Portland, OR: Portland State University.

[12] Bartone, P.T., Ursano, R.J., Wright, K.W., \& Ingraham, L.H. (1989), The impact of a military air disaster on the health of assistance workers: a prospective study, Journal of Nervous and Mental Disease, 177, 317-328.

[13] Wagnild, G.M., \& Young, H.M. (1993), Development and psychometric evaluation of the Resilience Scale, Journal of Nursing Measurement, 1, 165-178.

[14] Smith, C., \& Carlson, B.E. (1997), Stress, coping, and resilience in children and youth, Social Service Review, 71 (2), 231-256.

[15] Rew, L., \& Horner, S.D. (2003), Personal strengths of homeless adolescents living in a high-risk environment, Advances in Nursing Science, 26 (2), 90-101. 
[16] Smith, B.W., Dalen, J., Wiggins, K., Tooley, E., Christopher, P., \& Bernard, J. (2008), The Brief Resilience Scale: Assessing the ability to bounce back, International Journal of Behavioral Medicine, 15 (3), 194-200.

[17] Tusaie, K., \& Dyer, J. (2004), Resilience: A historical review of the construct, Holistic Nursing Practice, 18 (1), 3-8.

[18] Ahern, N.R., Kiehl, E.M., Sole, M.L., \& Byers, J. (2006), A review of instruments measuring resilience, Issues in Comprehensive Pediatric Nursing, 29, 103-125.

[19] Ryff, C.D., \& Singer, B. (2003), Flourishing under fire: Resilience as a prototype of challenged thriving. In C.L.M. Keyes \& Haidt J. (Ed.), Flourishing: Positive psychology and the life well-lived (pp.15-36). Washington, DC: APA.

[20] Prati, G. (2010), Proprietà psicometriche della scala della resilienza disposizionale, Giornale di Psicologia, 4 (3), 249-257.

[21] Stratta, P., Riccardi, I., Di Cosimo, A., Cavicchio, A., Struglia, F., Daneluzzo, E., Capanna, C., \& Rossi, A. (2012), A validation study of the Italian version of the Resilience Scale for Adolescents (READ), Journal of Community Psychology, 40 (4), 479-485.

[22] Friborg, O., Hjemdal, O., Rosenvinge, J.H., \& Martinussen, M. (2003), A new rating scale for adult resilience: what are the central protective resources behind healthy adjustment? International Journal of Methods in Psychiatric Research, 12 (2), 65-76.

[23] Hjemdal, O., Friborg, O., Stiles, T.C., Rosenvinge, J.H., \& Martinussen, M. (2006), Resilience predicting psychiatric symptoms: a prospective study of protective factors and their role in adjustment to stressful life events, Clinical Psychology \& Psychotherapy, 13 (3), 194-201.

[24] Connor, K.M., \& Davidson, J.R.T. (2003), Development of a new resilience scale: The Connor-Davidson Resilience Scale (CDRISC), Depression and Anxiety, 18 (2), 76-82.

[25] Ryff, C.D. (1989), Happiness is everything, or is it? Explorations of the meaning of psychological well-being, Journal of Personality and Social Psychology, 57, 1069-1081.

[26] Keyes, C.L.M., Shmotkin, D., \& Ryff, C.D. (2002), Optimizing well-being: The empirical encounter of two traditions. Journal of Personality and Social Psychology, 82 (6), 1007-1022

[27] Ryff, C.D., \& Singer, B. (1998), The contours of positive human health, Psychological Inquiry, 9, 1-28.

[28] Ryan, R.M., \& Deci, E.L. (2001), On happiness and human potentials: A review of research on hedonic and eudaimonic wellbeing. Annual Review of Psychology, 52, 141-166.

[29] Kobasa, S.C., Maddi, S.R., \& Kahn, S. (1982), Hardiness and health: a prospective study, Journal of Personality and Social Psychology, 42, 168-177.

[30] Masten, A.S., Hubbard, J.J., Gest, S.D., Tellegen, A., Garmezy, N., \& Ramirez, M. (1999), Competence in the context of adversity: pathways to resilience and maladaptation from childhood to late adolescence, Development and Psychopathology, 11 (1), 143-169.

[31] Picardi, A., Bartone, P.T., Querci, R., Bitetti, T. et al. (2012), Development and validation of the Italian version of the 15-item Dispositional Resilience Scale, Rivista di Psichiatria, 47 (3), 231237.

[32] Gloria, A.M., Castellanos, J., Scull, N.C., \& Villegas, F.J. (2009), Psychological coping and well-being of male Latino undergraduates, Hispanic Journal of Behavioral Sciences, 31 (3), 317-339.

[33] Pallant, J.F., \& Lae, L. (2002), Sense of coherence, well-being, coping and personality factors: Further evaluation of the sense of coherence scale, Personality and Individual Differences, 33, 39-48.

[34] Martin, R.A., Puhlik-Doris, P., Larsen, G., Gray, J., \& Weir, K. (2003), Individual differences in uses of humor and their relation to psychological well-being: Development of the Humor Styles Questionnaire, Journal of Research in Personality, 37, 48-75.

[35] Paradise, A.W., \& Kernis, M.H. (2002). Self-esteem and Psychological Well-being: Implications of Fragile Self-esteem. Journal of Social and Clinical Psychology, 21, 345-361.

[36] Ruini, C., Ottolini, F., Rafanelli, C., Ryff, C.D., \& Fava, G.A. (2003), La validazione italiana delle Psychological Well-Being Scales (PWB), Rivista di Psichiatria, 38 (3), 117-130.

[37] Sagone, E., \& De Caroli, M.E. (in press), Relationships between psychological well-being and resilience in middle and late adolescents, Procedia - Social and Behavioral Sciences.

[38] De Caroli, M.E., \& Sagone, E. (in press), Generalized selfefficacy and well-being in adolescents with high vs. low scholastic self-efficacy, Procedia - Social and Behavioral Sciences.

[39] Fernandes, H.M., Vasconcelos-Raposo, J., \& Teixeira, C.M (2010), Preliminary analysis of the psychometric properties of
Ryff's scales of psychological well-being in Portuguese adolescents, The Spanish Journal of Psychology, 13 (2), 10321043.

[40] Ryff, C.D. \& Singer, B. (2006), Best news yet on the six-factor model of well-being, Social Science Research, 35, 1103-1119.

[41] Kishida, Y., Kitamura, T., Gatayama, R., Matsuoka, T. et al. (2004), Ryff's psychological well-being inventory: factorial structure and life history correlates among Japanese university students, Psychological Reports, 94 (1), 83-103.

[42] Van Dierendonck, D., Diaz, D., Rodriguez-Carvajal, R., Blanco, A., \& Moreno-Jimenez, B. (2008), Ryff's six factor model of psychological well-being: A Spanish exploration, Social Indicators Research, 87, 473-479.

[43] Diener, E., Emmons, R.A., Larsen, R.J., \& Griffin, S. (1985), The Satisfaction with Life Scale, Journal of Personality Assessment, 49, 1-5.

[44] Ryan, R.M., \& Frederick C.M. (1997), On energy, personality and health: Subjective vitality as a dynamic reflection of well-being, Journal of Personality, 65, 529-565.

[45] Scheier, M.F., \& Carver, C.S. (1992), Effects of optimism on psychological and physical well-being: Theoretical overview and empirical update, Cognitive Therapy and Research, 16, 201-228.

[46] Scheier, M.F., Carver, C.S., \& Bridges, M.W. (2001). Optimism, pessimism, and psychological well-being. In E.C. Chang (Ed.), Optimism and pessimism: Implications for theory, research, and practice (pp. 189-216). Washington, DC: American Psychological Association

[47] Lazarus, R.S., \& Folkman, S. (1984), Stress, appraisal, and coping. New York: Springer.

[48] Carver, C.S., Scheier, M.F., \& Weintraub, J.K. (1989), Assessing coping strategies: A theoretically based approach, Journal of Personality and Social Psychology, 56, 267-283.

[49] Scheier, M.F., \& Carver, C.S. (1987), Dispositional optimism and physical well-being: the influence of generalized expectancies on health, Journal of Personality, 55, 169-210.

[50] Hatchett, G.T., \& Park, H.L. (2004), Relationships among optimism, coping styles, psychopathology, and counseling outcome, Personality and Individual Differences, 36, 1755-1769.

[51] Kjeldstadli, K., Tyssen, R., Finset, A., Hem, E., Gude, T. Gronvold, N.T., Ekeberg, O., \& Vaglum, P. (2006), Life satisfaction and resilience in medical school - a six year longitudinal, nationwide and comparative study, BMC Medical Education, 6 (48).

[52] Copeland, E.P., \& Hess, R.S. (1995), Differences in young adolescents' coping strategies based on gender and ethnicity, Journal of Early Adolescence, 15, 203-219.

[53] Matud, M.P. (2004), Gender differences in stress and coping styles, Personality and Individual Differences, 37 (7), 1401-1415.

[54] Folkman, S., \& Lazarus, R.S. (1988). Ways of Coping Questionnaire. Palo Alto, CA: Consulting, Psychological Press.

[55] Endler, N.S., \& Parker, J.D.A. (1990), Multidimensional assessment of coping: A critical evaluation, Journal of Personality and Social psychology, 58, 844-854.

[56] Carver, C.S. (1997). You want to measure coping but your protocol is too long: Consider the brief cope. International Journal of Behavioral Medicine, 4 (1), pp.92-100.

[57] Sica, C., Magni, C., Ghisi, M., Altoè, G., Sighinolfi, C., Chiri, L.R., \& Franceschini, F. (2008), Coping Orientation to Problems Experienced-Nuova Versione Italiana (COPE-NVI): uno strumento per la misura degli stili di coping, Psicoterapia cognitiva e comportamentale, 14 (1), 27-53.

[58] Ryff, C.D., \& Keyes, C.L.M. (1995), The structure of psychological well-being revisited, Journal of Personality and Social Psychology, 69, 719-727.

[59] Zani B., \& Cicognani, E. (1999), Le vie del benessere, Roma: Carocci.

[60] Ryff, C.D., \& Singer, B. (1996), Psychological Well-Being: Meaning, Measurement, and Implications for Psychotherapy Research, Psychotherapy and Psychosomatics, 65, 14-23.

[61] Li, M., Yang, Y. (2009), Determinants of Problem Solving, Social Support Seeking, and Avoidance: A Path Analytic Model, International Journal of Stress Management, 16 (3), 155-176.

[62] Beasley, M., Thompson, T., \& Davidson, J. (2003), Resilience in response to life stress: the effects of coping style and cognitive hardiness, Personality and Individual Differences, 34 (1), 77-95.

[63] Hurtes, K.P., Allen, L.R. (2001), Measuring Resiliency in Youth: The Resiliency Attitudes and Skills Profile, Therapeutic Recreation Journal, 35 (4), 333-347. 
[64] Park, C.L., \& Adler, N.E. (2003), Coping style as a predictor of health and well-being across the first year of medical school, Health Psychology, 22 (6), 627-631.

[65] Kazarian, S.S., \& Martin, R.A. (2004), Humor styles, personality, and well-being among Lebanese university students, European Journal of Personality, 18 (3), 209-219.

[66] Maltby, J., Lewis, C.A., \& Day, L. (1999), Religious orientation and psychological well-being: The role of the frequency of personal prayer, British Journal of Health Psychology, 4 (4), 363378.

[67] Dipboye, R.L., \& Phillips, A.P. (1990), College students' time management: Correlations with academic performance and stress, Journal of Educational Psychology, 82, 760-768.

[68] Hsin Chun Chu, A., \& Nan Choi, J. (2005), Rethinking procrastination: Positive effects of "active" procrastination behavior on attitudes and performance, Journal of Social Psychology, 145 (3), 245-264.

[69] Martin, A.J. (2002), Motivation and academic resilience: Developing a model for student enhancement, Australian Journal of Education, 46 (1), 34-49.

[70] Martin, A.J., \& Marsh, H.W. (2006), Academic resilience and its psychological and educational correlates: A construct validity approach, Psychology in the Schools, 43 (3), 267-281.

[71] Bandura, A. (1997). Self-efficacy: The exercise of control. New York: Freeman.

[72] Yusuf, M. (2011), The impact of self-efficacy, achievement motivation, and self-regulated learning strategies on student's academic achievement, Procedia - Social and Behavioral Sciences, 15, 2623-2626. 